\section{and against}

Czech Conroy, Energy Campaigner for Friends of the Earth in the UK, argues that an oxide fuel reprocessing plant should not be built

REPROCESSING-- the extraction of plutonium and uranium from nuclear fuel elements after they have left the reactor - originated as a key step in nuclear weapons programmes. The initial financial and intellectual commitment to the technology then resulted in nuclear weapons states, and some other countries, regarding reprocessing as a desirable -if not an inevitable - step in all radioactive waste management. (Interestingly Canada, which is not a nuclear weapons state, has no plans to reprocess its spent fuel and has never regarded reprocessing as necessary or desirable). In October 1976 the United States followed Canada in this respect when President Ford announced: "I have decided that the United States should no longer regard reprocessing of used nuclear fuel to produce plutonium as a necessary and inevitable step in the nuclear fuel cycle [and that] avoidance of proliferation must take precedence over economic interests." In the same year British Nuclear Fuels Ltd (BNFL) applied for planning permission to build a Thermal Oxide-fuel Reprocessing Plant (THORP) at Windscale in Cumbria, and at the resulting inquiry into their application they argued that reprocessing was necessary and desirable for radioactive waste management.

To date UK experience of reprocessing has been confined almost exclusively to uranium metal fuel, either from the military programme or from the Magnox reactors which formed the first phase of Britain's civil nuclear programme. The cladding of this fuel is a magnesium alloy which corrodes significantly after two years' storage in water, leading the Royal Commission on Environmental Pollution (RCEP) to conclude in 1976 in its report Nuclear Power and the Environment that "There appears to be no real alternative to the reprocessing of Magnox fuels ..." By 1977, however, Sir Brian Flowers, former chairman of RCEP, had come round to the view that Magnox reprocessing might not be necessary since Magnox fuel can also be stored in gas before disposal-a much more corrosion-resistant environment than water.

The fuel elements which THORP would reprocess would be clad in more corrosion-resistant materials than Magnox fuel - stainless steel for British oxide fuel elements and a zirconium alloy (zircaloy) for foreign fuel elements. Nevertheless, BNFL argued at the Windscale Inquiry that the corrosion of stainless-steel-clad fuel elements might be high if the elements were stored in water for more than ten years. Objectors to THORP argued that improvements in the water chemistry of storage ponds would reduce corrosion levels, and that like Magnox fuel elements the stainless-steel-clad ones could be stored in gas.

The United States plans to store its spent fuel for several years while it decides whether or not to recover the plutonium and uranium. If the spent fuel were not reprocessed it would be put in overpack canisters and disposed of in a geologic repository. It is sometimes argued that, since the fuel elements would contain all the radiologically hazardous plutonium produced, it would be preferable to reprocess the fuel and recycle the plutonium in thermal or fast reactors.

This argument, however, overlooks the fact that the thermal or fast reactor fuel containing the plutonium must also be disposed of ultimately, and when these and other wastes are taken into account the amount of plutonium to

Czech Conroy's book What Choice Windscale? The Issues of Reprocessing, is published by Friends of the Earth and the Conservation Society (February 1978, price £1). be disposed of under the reprocessing route is only between five and ten times less than that under the direct disposal route. Since "recycling of plutonium requires reprocessing, mixed oxide fabrication, and management of various additional types of waste, all of which raise serious questions of economics, health and safety, and environmental matters" (Nuclear Fuel Cycles and Waste Management, p27 New York; American Physical Society, 1977), many people believe that waste management options involving reprocessing do not reduce the radiological hazards of nuclear waste.

Another argument advanced in favour of reprocessing is that the uranium and plutonium which would be recovered will be essential in the future if we are to meet official forecasts of energy demand. These forecasts have been criticised at the Windscale Inquiry and elsewhere on simple matters of principle. Work carried out at a variety of research establishments in the UK and elsewhere suggests that a combination of conservation and renewable energy technology systems can substitute for oil and gas more rapidly and cheaply than plutonium-fuelled fast reactors, thereby eliminating any need for plutonium as a fuel. In any case, deferral of a decision on THORP need not affect feasible fast breeder programmes since by 2000 a further 50 or so tonnes of plutonium could be extracted from Magnox fuel.

Although oxide reprocessing is not particularly attractive either from the standpoint of reducing radiological hazards or providing fuel, its supporters claim that it could have economic advantages over the alternatives. But oxide fuel reprocessing has not been demonstrated on a commercial scale anywhere in the world, and its estimated costs have soared rapidly during the last few years so that the United States government now doubts whether it is economically viable. Nevertheless, if BNFL's cost estimates are accurate, reprocessing nuclear fuels through the THORP plant and recycling the plutonium and uranium will almost certainly be cheaper than storage and direct disposal of the spent fuel, since foreign customers are prepared to sign very unfavourable contracts to get rid of their spent fuel. Uranium prices would have to fall well below $\$ 30 / \mathrm{lb}$ before it would become cheaper to buy fresh uranium than to recycle uranium and plutonium. The price of uranium will be influenced to a large extent by uranium requirements and hence future levels of installed nuclear generating capacity - so that as forecasts of nuclear capacity rapidly decline the relative economic advantage of reprocessing is also likely to decline. A case can be made, however, for proceeding with THORP on economic grounds.

Against the probable economic benefits of THORP must be set its external costs. Outside the area of radioactive waste management these costs relate primarily to the possible use of plutonium as a nuclear explosive, particularly by national governments. Increasing recognition of this risk has resulted in the establishment of the two-year International Fuel Cycle Evaluation programme (INFCE), in which Britain is participating. The primary function of INFCE is to identify technically and economically feasible technologies which are more proliferation-resistant than the kind of oxide reprocessing BNFL is proposing to carry out. Meanwhile, there is a belief that the construction by Britain of a plant for the separation and distribution of nuclear-weapon material would be politically catastrophic.

The relative weights to attach to any economic gains from oxide reprocessing, its ultimate impact on the fabric of society, and the possibility of it increasing the risk of nuclear war are a matter of political and ethical judgment. Like President Ford, I believe that “. . . avoidance of proliferation must take precedence over economic interests". We shall soon see whether or not the British Government believes that too. 